\title{
Evaluation of the Effects of Platelet-Rich Plasma on Follicular and Endometrial Growth: A Literature Review
}

\author{
Adrielli Riboldi Ferrari ${ }^{1}$, Sylvia Cortrezzi ${ }^{1}$, Edson Borges Junior ${ }^{1}$, Daniela Braga ${ }^{1}$, Maria do Carmo Borges de \\ Souza², Roberto de Azevedo Antunes ${ }^{2}$
}

${ }^{1}$ Fertility - Centro de Fertilização Assistida, São Paulo, SP, Brazil

${ }^{2}$ Fertipraxis, Human Reproduction Center. Rio de Janeiro, RJ, Brazil

\begin{abstract}
Platelet-rich plasma (PRP) has been used in several areas of medicine due to its ability to promote tissue regeneration by growth factors and cytokines. This review addresses the use of PRP to rejuvenate ovarian follicles and increase the thickness of the endometrium to receive an embryo. PRP is obtained from the patient's own blood (autologous blood) - a fact that determines a lower chance of rejection reactions. Alpha granules of platelets provide and release supra physiological amounts of growth factors and cytokines, which provide a regenerative stimulus in tissues with low healing potential. In the ovary, PRP and its growth factors stimulate vascularization and recruitment of available primordial follicles that could no longer be otherwise stimulated. The rejuvenation of the ovary by PRP infusion aims to obtain new oocytes in ovaries with low numbers of follicles or low follicular reserve markers. In the preparation of the endometrium, PRP is used for its several growth factors that allow tissue proliferation and endometrial thickening, especially in cases of endometria that are difficult to prepare or that fail to reach an adequate minimum thickness $(>7 \mathrm{~mm})$. To date, there are few studies of greater expression in the literature that support the use of PRP with the two purposes described above. Thus, although promising, the technique must still be validated by larger clinical trials.
\end{abstract}

Keywords: platelet-rich plasma, platelet-rich plasma, review

\section{INTRODUCTION}

A recent increase in new autologous cycles of in vitro fertilization (IVF) and intracytoplasmic sperm injection (ICSI) has been reported by the latest report issued by the Latin American Society of Assisted Reproduction (REDLARA). It has been described that $40.9 \%$ of women undergoing new cycles were aged 35 to 39 years and that $31.1 \%$ were aged 40 years or older (Zegers-Hochschild et al., 2019). Infertility refers to the failure of conception by a couple and is known as a multifactorial syndrome in all cultures and societies (Alam et al., 2019).

Infertility is common, with recent publications describing prevalence ranging between $9 \%$ and $18 \%$ in the general population (Aghajanova et al., 2017). According to the National Summary Report of the Society for Assisted Reproductive Technology, a total of 43,098 IVF cycles were performed in 2018 (data: 12 $2^{\text {th }}$ SisEmbrio report, 2020).

There is a growing body of data supporting the idea that infertility has implications that go beyond the patient's immediate reproductive needs. Approximately 5\% to $10 \%$ of infertile women may have underlying genetic abnormalities, such as chromosomal aberrations, single or multiple genetic mutations and polymorphisms. A significant portion of infertility may be explained, at least in part, by exposure to environmental factors, endocrine disrupters and hormonal imbalances that not only may jeopardize reproductive health, but also increase later-life morbidity and mortality (Tarín et al., 2015).

The negative impact of infertility and its treatments is generally attributed to the stress caused by the inability to conceive, especially due to scheduled sexual intercourse, negative effects of the treatment (both on physical and psychological wellbeing), and pressure from family members and people around the couple. Compared to men, infertile women seem to be more stressed and more likely to develop sexual dysfunction, with great variability in their subjective experiences, as well as in the difficulties encountered during treatment (Facchin et al., 2019).

For Sills \& Wood (2019), an intractable problem in clinical infertility is a low (or absent) ovarian reserve, which in turn reflects the natural depletion of oocytes associated with advancing maternal age, since the number of available oocytes has generally been considered finite and limited.

To increase follicular and tissue growth, platelet concentrates such as Platelet-Rich Plasma (PRP) have been used in tissue regeneration due to the high concentration of growth factors contained in platelets. When activated, platelets release high amounts of growth factors such as PDGF (platelet-derived growth factor), TGF-b1 (transformation growth factor b1), IGF-I (insulin-like growth factor-1) and VEGF (endothelial vascular growth factor), which promote cell proliferation and differentiation, chemotaxis and angiogenesis, thus optimizing the regenerative process (Lichtenfels, 2012).

The application of PRP in a reproductive context was an innovation considered for the first time only a few years ago by Pantos et al. (2019), when a group of patients with poor prognosis infertility received intra-ovarian injections of PRP followed by in vitro fertilization with their own oocytes (Sills \& Wood, 2019).

Knowing that adequate endometrial thickness is a critical factor for embryo implantation, Chang et al. (2015) conducted a study that investigated the effects of PRP in women with thin endometria $(<7 \mathrm{~mm})$. In its encouraging results, a significant increase in endometrial thickness was shown in individuals given PRP infusion compared to controls (not administered PRP).

Treatment with PRP might improve the outcomes of patients with decreased endometrial thickness $(<7 \mathrm{~mm})$ undergoing IVF cycles and even of individuals on hormonal therapy. One of the most important phases of Assisted Reproductive Technology (ART) treatment is, undoubtedly, embryo transfer and implantation; successful therapy requires, in addition to a competent embryo, a receptive endometrium. The objective of this paper is to review literature on the effects of PRP on follicular and endometrial growth.

\section{MATERIALS AND METHODS}

The articles featured in this literature review were searched on PubMed and Google Scholar database and 
included papers published in the period of 2009-2019 in Portuguese and English. The following keywords in English were used: "PRP AND human fertilization", "PRP AND growth factor", "PRP AND follicle growth", "PRP AND ovarian", "PRP AND folliculogenesis", "Platelet-rich plasma", "Platelet-rich plasma AND endometrium"; and the following keywords in Portuguese were used: "crescimento folicular e endometrial", "plasma rico em plaquetas na reprodução humana", "plasma rico em plaquetas". Additional papers were searched from the references cited in the found articles (Table 1).

After searching the databases for articles and applying the defined search strategies, the articles were read and translated from the original version only after determining whether, based on their abstracts, the studies met the eligibility criteria; only then were they included in the review.

\section{LITERATURE REVIEW}

\section{Folliculogenesis}

Ovarian follicles are structures generated in the ovaries that have two major functions, the production of hormones and gametes. Ovarian follicles may develop until ovulation or undergo atresia though the control of the hypothalamic-pituitary-gonadal axis (Zhou et al., 2019). The reason why some oocytes develop and others in the same cohort undergo atresia is unknown (Britt, 2008).
However, it is known that early antral follicles do not necessarily grow coordinately in response to exogenous gonadotropins to achieve simultaneous functional and morphological maturation, and that not necessarily all follicles that respond to $\mathrm{FSH}$ express sufficient $\mathrm{LH}$ receptors to respond to the signal from maturation (Kahraman et al., 2017).

Due to hypersecretion of LH causing premature oocyte maturation, the decline in female infertility has been mitigated, as younger oocytes have a better balance of cellular activity compared to aged oocytes. During the process of folliculogenesis, the oocyte undergoes a significant set of genetic, epigenetic and cytoplasmic changes in order to attain proficiency in fertilization. This entire course of events depends on a continuous interaction between oocytes and granulosa cells that safeguard the coordination of all events sequenced in the ovary under the influence of paracrine and endocrine factors (Alam et al., 2019).

\section{Growth Factors Found in PRP (Figure 1)}

Platelets are known for their main function of preventing blood loss in vascular injury sites through interactions between platelets and proteins, which cause the formation of fibrin clots. (Fabi \& Sundaram, 2014). The chemical composition and morphology of platelets is understood as presenting an outer portion, the phospholipid membrane,

Table 1. Brief description of the main authors and their characteristics for the construction of the bibliographic review.

\begin{tabular}{|c|c|c|c|c|}
\hline AUTHORS/YEAR & OBJECTIVE & DATABASE & KEYWORDS & $\begin{array}{l}\text { INCLUSION } \\
\text { CRITERIA }\end{array}$ \\
\hline $\begin{array}{l}\text { Farimani et al. } \\
\text { (2019) }\end{array}$ & $\begin{array}{l}\text { Intra-ovarian } \\
\text { injection in women } \\
\text { with POR. }\end{array}$ & PubMed & $\begin{array}{l}\text { "PRP AND follicle growth", } \\
\text { "PRP AND ovarian", PRP } \\
\text { AND folliculogenesis", } \\
\text { "Platelet-rich plasma". }\end{array}$ & $\begin{array}{l}\text { It matches the sought } \\
\text { subject; text in English; } \\
\text { time period; included } \\
\text { humans. }\end{array}$ \\
\hline $\begin{array}{l}\text { Pantos et al. } \\
\text { (2019) }\end{array}$ & $\begin{array}{l}\text { Case report of women } \\
\text { with ovarian failure. }\end{array}$ & $\begin{array}{l}\text { PubMed, } \\
\text { Google } \\
\text { Scholar }\end{array}$ & $\begin{array}{l}\text { "PRP AND follicle growth", } \\
\text { "PRP AND ovarian", PRP } \\
\text { AND folliculogenesis", } \\
\text { "Platelet-rich plasma". }\end{array}$ & $\begin{array}{l}\text { Text in English; case } \\
\text { report recently published } \\
\text { including humans. }\end{array}$ \\
\hline $\begin{array}{l}\text { Kim et al. } \\
(2019)\end{array}$ & $\begin{array}{l}\text { Use of PRP in thin } \\
\text { endometrium }\end{array}$ & PubMed & $\begin{array}{l}\text { "autologous PRP AND } \\
\text { endometrium" }\end{array}$ & $\begin{array}{l}\text { Prospective study } \\
\text { describing the PRP } \\
\text { preparation technique. }\end{array}$ \\
\hline $\begin{array}{l}\text { Sfakianoudis et al. } \\
\text { (2019) }\end{array}$ & $\begin{array}{l}\text { PRP infusion and } \\
\text { ovarian response }\end{array}$ & PubMed & $\begin{array}{l}\text { "PRP AND follicle growth", } \\
\text { "PRP AND ovarian", PRP } \\
\text { AND folliculogenesis." }\end{array}$ & $\begin{array}{l}\text { Publication within the } \\
\text { chosen time period; text } \\
\text { in English; study with } \\
\text { humans. }\end{array}$ \\
\hline $\begin{array}{l}\text { Molina et al. } \\
(2018)\end{array}$ & $\begin{array}{l}\text { Endometrial } \\
\text { preparation with PRP }\end{array}$ & PubMed & $\begin{array}{l}\text { "PRP AND endometrial } \\
\text { preparation" }\end{array}$ & $\begin{array}{l}\text { Brazilian publication; } \\
\text { optimistic results; study } \\
\text { enrolled women. }\end{array}$ \\
\hline $\begin{array}{l}\text { Jang et al. } \\
\text { (2017) }\end{array}$ & $\begin{array}{l}\text { Injection of } \\
\text { intrauterine PRP in } 60 \\
\text { rats. }\end{array}$ & PubMed & "PRP AND endometrium" & $\begin{array}{l}\text { Publication of experimental } \\
\text { character and of good } \\
\text { relevance. }\end{array}$ \\
\hline $\begin{array}{l}\text { Zadehmodarres et al. } \\
\text { (2017) }\end{array}$ & $\begin{array}{l}\text { Intrauterine PRP } \\
\text { injection in } 10 \text { women }\end{array}$ & PubMed & "PRP AND endometrium" & $\begin{array}{l}\text { Pilot study, but with } \\
\text { several citations in relevant } \\
\text { studies. }\end{array}$ \\
\hline $\begin{array}{l}\text { Farimani et al. } \\
(2016)\end{array}$ & $\begin{array}{l}\text { Intrauterine } \\
\text { administration of PRP. }\end{array}$ & $\begin{array}{l}\text { PubMed, } \\
\text { Google } \\
\text { Scholar }\end{array}$ & $\begin{array}{l}\text { "PRP AND ovarian", } \\
\text { "crescimento folicular e } \\
\text { endometrial" }\end{array}$ & $\begin{array}{l}\text { Publication translated from } \\
\text { English into Portuguese, } \\
\text { with reports of studies in } \\
\text { humans. }\end{array}$ \\
\hline $\begin{array}{l}\text { Chang et al. } \\
(2015)\end{array}$ & $\begin{array}{l}\text { Report of minimum } \\
\text { endometrial thickness } \\
\text { and intrauterine } \\
\text { administration of PRP. }\end{array}$ & $\begin{array}{l}\text { PubMed, } \\
\text { Google } \\
\text { Scholar }\end{array}$ & $\begin{array}{l}\text { "PRP AND ovarian", } \\
\text { "Platelet-rich plasma AND } \\
\text { endometrium", } \\
\text { "crescimento folicular e } \\
\text { endometrial" }\end{array}$ & $\begin{array}{l}\text { Renowned publication; } \\
\text { text in English; report of } \\
\text { studies in humans. }\end{array}$ \\
\hline
\end{tabular}




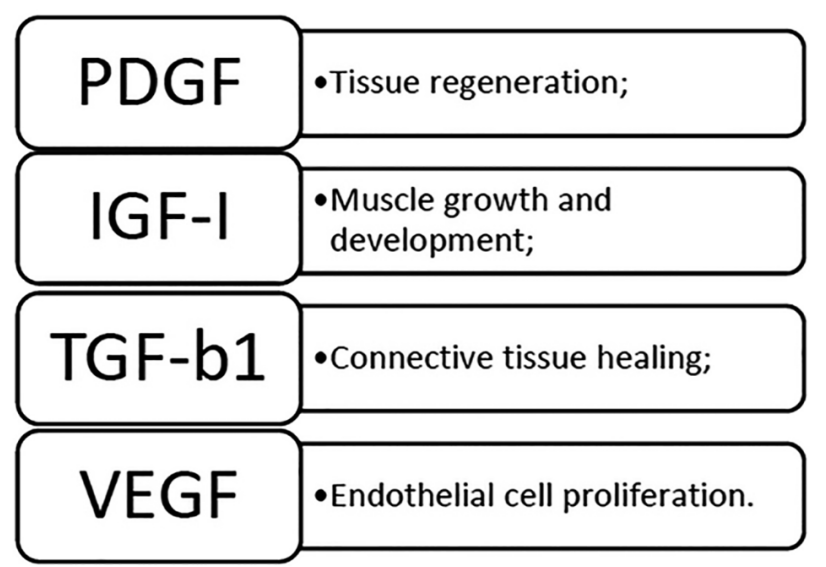

Figure 1. Most common growth factors in PRP and their main functions.

and an inner portion where microtubules, dense granules, a-granules, dense tubular system, mitochondria, glycogen reserve are found. Platelets interfere with primary hemostasis through the properties of their membranes and the content of their cytoplasmic organelles (Grassi \& Araujo, 2012).

PDGF is very important because it is the first component to be present at the injury site; it is also one of the most abundant factors present in PRP preparations together with TGF, which aid in the migration and proliferation of human osteoblast cell lines (Casati et al., 2014). PDGF is known to increase cell recruitment, proliferation and differentiation, although it also plays a role in angiogenesis and inflammation (Du et al., 2018). This factor has been used to accelerate tissue regeneration, alone or in combination with other growth factors.

IGF-I, also known as sulfation factor and somatome-

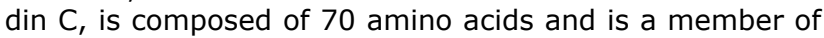
the insulin family. Its function is to stimulate production, differentiation, migration, survival and metabolism. It acts through IGF-1R, which is predominant in the body, where it belongs to the family of tyrosine kinase receptors and is phosphorylated by IGF-I (Deochand et al., 2016).

One of the potential chemo attractants includes transforming growth factor $\beta 1$ (TGF- $\beta 1$ ). TGF-b1 may be involved in signaling events related to proliferation, differentiation and recruitment of parents to the injury site, in order to initiate regeneration, acting as a stimulating factor for tissue repair (Gonçalves et al., 2016).

TGF- $\beta 1$ stimulates VEGF expression and secretion of immortalized human granulosa-lutein (hGL) cells and primary hGL cells. The levels of TGF- $\beta 1$ and VEGF protein are increased in the follicular fluid of patients, and the levels of these two proteins in the follicular fluid have been positively correlated (Fang et al., 2020).

VEGF, a secreted protein specific to the endothelium, plays an important role in angiogenesis (Zhang et al., 2016). A study by Nayak \& Dinda (2015) observed a peak of VEGF at the beginning of the proliferative phase and in the glands during the secretory phase favoring the pre-implantation period due to the action of progesterone.

\section{Platelet-Rich Plasma (PRP)}

PRP is a plasma preparation enriched with a platelet concentration above that normally contained in whole blood (Malanga \& Goldin, 2014). Protocols include one or two centrifugation steps to separate whole blood into three layers: an upper layer of plasma, a buffy coat, and red blood cells (RBC) at the bottom. The rationale for the use and therapeutic potential of preparations with a high concentration of platelets is based on their ability to supply and release supra physiological amounts of essential growth factors and cytokines from their alpha granules to provide a regenerative stimulus that increases healing and promotes repair in tissues with low healing potential (Davis et al., 2014).

The main functions of platelets include the prevention of acute blood loss and the repair of vascular walls and surrounding tissues after injury. During healing, platelets are activated and aggregated to release granules containing growth factors that stimulate the inflammatory cascade and the healing process. Through the activation of platelets in PRP, cytokines and growth factors become bioactive and are secreted within ten minutes of coagulation. They can regulate cell migration, fixation, proliferation and differentiation and promote the accumulation of extracellular matrix (Chang et al., 2015).

During the initial stages of wound repair, activated platelets attract and stimulate cell migration to the wound, aggregating and forming a fibrin matrix. This matrix then serves as a tissue scaffold for the sustained release of platelets and cytokine growth factors, which stimulate cell recruitment, differentiation and communication (Scherer et al., 2012).

Borzini \& Mazzucco (2007) reported in their literature review article that the application of PRP varies in various clinical settings involving skin, bone, dental, maxillofacial surgery, diabetic foot and leg, cardiac and vascular surgery, tympanic, eye and corneal lesions, nerve injuries, spinal fusion, burns, cosmetic surgery and facelifts. Most of these studies have shown positive, encouraging results. Despite the evidence on the biological mechanisms that support the clinical efficacy of platelets, it should be considered that the technical aspect of PRP preparation is closely related to its clinical effects. Therefore, lack of standardization of PRP preparation techniques in different studies may be related to the lack of effectiveness described by some authors.

The wide variability in PRP formulations creates a challenge to accurately extract conclusions from the literature to guide PRP production and determine indications for use, leading to the development of PRP classification schemes to facilitate investigations in clinics (Delong et al., 2012; Mishra et al., 2012).

Recently, Dawood \& Salem (2018) presented the steps of a representative method of preparing the PRP. However, PRP preparations can be classified according to the preparation method, the sample content and the proposed application. Preparations vary in terms of centrifugation speed, centrifugation time and use of anticoagulants, while the content varies according to the predominant constituent (e.g.: platelets, leukocytes or growth factors).

The methodologies for PRP preparation are still under development, and different preparation protocols have emerged, from conventional blood centrifugation to commercial systems such as activation by the addition of collagen, calcium and/or thrombin, by contact with the glass tube, or by cycles of cryopreservation (Mazzucco et al., 2009).

Roh et al. (2016) demonstrated that PRP activated with a mixture of thrombin and calcium significantly increased the release of growth factors over seven days compared with non-activated PRP. However, there is uncertainty regarding the speed (Scherer et al., 2012).

Activation causes the granules present in the platelets to fuse with their cell membrane (also called degranulation), where secretory proteins (for example, PDGF, TGF- $\beta$ etc.) are transformed into a bioactive state by the addition of histones and side chains of carbohydrates. The active proteins are then secreted, binding to the transmembrane 
receptors of the target cells, which include mesenchymal stem cells, osteoblasts, fibroblasts, endothelial cells and epidermal cells. The agonists bind to transmembrane receptors, then activate an intracellular signal protein that causes the expression of a sequence of genes that directs cell proliferation, matrix formation, osteoid production, collagen synthesis, etc., thus causing repair and tissue regeneration (Dhurat \& Sukesh, 2014).

No evidence has been found about the ideal activator concentration needed to trigger the optimal release of growth factors during the PRP activation process, and different concentrations may therefore lead to different results (Jo et al., 2013).

Despite these variations, all protocols follow a generic sequence consisting of blood collection, initial centrifugation to separate red blood cells, subsequent centrifugation cycles to concentrate platelets and other components, and the activation of the sample by adding a platelet agonist (Dhurat \& Sukesh, 2014).

\section{Effect of PRP on Follicular Growth}

PRP therapy has been investigated in women with premature ovarian failure (POF), infertile women over 35 and women with a low ovarian reserve. In this procedure, PRP is injected into the ovary under ultrasound guidance (Dawood \& Salem, 2018).

Until 2011, there was no clear definition of poor responder patients (PORs), which led to a significant degree of confusion. However, the introduction of the Bologna criteria allowed the description of a very heterogeneous group of patients with very different success rates after ART. This has led to the recent development of the POSEIDON (Patient-Oriented Strategies Encompassing Individualized Oocyte Number) criteria for POR, which stratified patients into more homogeneous subgroups and, more importantly, produced recommendations for clinical management. The treatment of patients with POR requires an individualized approach (Haahr et al., 2018).

The Bologna criteria published in 2011 by the European Society for Human Reproduction and Embryology (ESHRE) were established mainly to define the population with POR based on strict criteria. The underlying idea was that this would allow the definition of more homogeneous groups when new treatments for POR were compared (Ferraretti et al., 2011). Although the Bologna criteria were a crucial step in defining POR, it was clear that the criteria did not adequately take into account the age-related impacts on oocyte quality, which obviously affects success rates (Haahr et al., 2018). The POSEIDON classification subdivides patients into four subgroups based on quantitative and qualitative parameters (Haahr et al., 2018).

Sfakianoudis et al. (2019) described ovarian PRP infusion as an efficient model to determine the successful management of patients with poor ovarian response. Given the highly angiogenic structure of the ovary and the critical role of various platelet-derived factors in vascular activation and stabilization, treatment with PRP might likely enrich the dysfunctional ovarian tissue of patients with factors essential for neoangiogenesis, leading to tissue regeneration and reactivation.

In an investigation about intra-ovarian PRP injection in women with POR, a study by Farimani et al. (2019) reported an increase in the average number of oocytes before and after PRP injection from 0.64 to 2.1 . The results of this study appear to be the first to report on the effects of intra-ovarian PRP injection on the ovarian response to controlled ovarian stimulation.

In a recently published report, Pantos et al. (2019) analyzed patients with a history of implantation failure after IVF who rejected the option of having donor eggs and received treatment with autologous ovarian PRP; pregnancies by natural conception were achieved within two to six months of treatment with PRP.

Studying rats with polycystic ovary syndrome, Seyyed Anvari et al. (2019) demonstrated that PRP infusion decreased follicular atresia and notably improved follicular growth.

Considering the angiogenic composition of the ovary and the fundamental influence of PDGF on vascular activation and stabilization, treatment with autologous PRP may be seen as a facilitator of regeneration of ovarian tissue (Bos-Mikich et al., 2018).

\section{Effect of PRP on Endometrial Thickness}

Successful embryo implantation requires a good quality embryo and a receptive endometrium. It was found that adequate endometrial growth is necessary for successful implantation (Colombo et al., 2017).

The endometrium plays a pivotal role in implantation and pregnancy. The pregnancy rate increases as endometrial thickness grows. For Chang et al. (2015), the minimum endometrial thickness necessary for embryo transfer is $7 \mathrm{~mm}$ at the end of the follicular phase. Noyes et al. (1995) reported a significantly higher pregnancy rate $(48.6 \%)$ in patients with an endometrial thickness $>9 \mathrm{~mm}$, compared with $16 \%$ in individuals with an endometrial thickness $<9 \mathrm{~mm}$ (apud Coksuer et al., 2019).

Intrauterine PRP infusion is a new approach that has been suggested for the treatment of recurrent implantation failures (Chang et al., 2015). Although it is not clear how intrauterine PRP administration acts to increase endometrial thickness, studies have found a positive increase in endometrial thickness, leading to higher pregnancy rates.

A pilot study by Zadehmodarres et al. (2017) included 10 patients with a history of cycle cancelation due to decreased endometrial thickness $(<7 \mathrm{~mm})$. Endometrial thickness increased 48 hours after the first PRP application and reached more than $7 \mathrm{~mm}$ after the second PRP application in all patients. Embryo transfers were performed in all patients; five became pregnant and four pregnancies progressed normally. PRP enabled endometrial growth in patients with thin endometria.

Chang et al. (2015) administered intrauterine PRP to infertile women with thin endometria and reported that endometrial thickness increased $>7 \mathrm{~mm}$ within $48-72$ hours of PRP infusion in all five patients. All patients became pregnant, with four pregnancies progressing to full term. In a pilot study, Farimani et al. (2016) performed intrauterine administration of PRP 36 hours prior to frozen embryo transfers. The six women included in the study became pregnant.

Despite the lack of specific studies evaluating the effects of PRP on the endometrium, Jang et al. (2017) analyzed damaged endometrial tissue of 60 rats and found faster endometrial regeneration after PRP injection. This shows that its main growth factor, PDGF, plays an important role in cell proliferation within the endometrium.

Kim et al. (2019) reported the use of PRP in women with refractory thin endometrium. The authors clearly described the techniques used to prepare PRP, including the amounts of sample used and the speed of centrifugation. This study, which included women with two or more IVF attempts and refractory thin endometria, reported improved implantation, pregnancy and live birth rates. Treatment with intrauterine PRP seems not only to promote endometrial growth in patients with thin endometria, but also to positively affect assisted reproduction outcomes.

\section{CONCLUSION}

PRP has positive, promising impacts on endometrial and follicular growth with the added benefit of using 
autologous blood, which decreases the chances of adverse reactions and effects. PRP has become an alternative for older women with low follicular reserve and unresponsive endometria who wish to become mothers. The outcomes must be further evaluated to confirm the safety and effectiveness of PRP in gynecology.

\section{CONFLICT OF INTERESTS}

The authors have no conflict of interest to declare.

\section{Corresponding author:}

Adrielli Riboldi Ferrari

Fertility - Centro de Fertilização Assistida

São Paulo/SP, Brazil

E-mail: adririboldi@hotmail.com

\section{REFERENCES}

Aghajanova L, Hoffman J, Mok-Lin E, Herndon CN. Obstetrics and Gynecology Residency and Fertility Needs. Reprod Sci. 2017;24:428-34. PMID: 27368879 DOI: $10.1177 / 1933719116657193$

Alam F, Khan TA, Amjad S, Rehman R. Association of oxidative stress with female infertility - A case control study. J Pak Med Assoc. 2019;69:627-31. PMID: 31105280

Borzini P, Mazzucco I. Platelet-rich plasma (PRP) and platelet derivatives for topical therapy. What is true from the biologic view point? ISBT Sci Ser. 2007;2:272-81.

Bos-Mikich A, de Oliveira R, Frantz N. Platelet-rich plasma therapy and reproductive medicine. J Assist Reprod Genet. 2018;35:753-6. PMID: 29564738 DOI: $10.1007 /$ s10815018-1159-8

Brazil. Ministry of Health. ANVISA. SisEmbrio - 12th SisEmbrio report. Brasília: ANVISA; 2020. Portuguese. Available at: https://www.gov.br/anvisa/pt-br/centraisdeconteudo/publicacoes/sangue-tecidos-celulas-e-orgaos/ relatorios-de-producao-de-embrioes-sisembrio/12o-relatorio-do-sistema-nacional-de-producao-de-embrioes-sisembrio/view

Britt $\mathrm{JH}$. Oocyte development in cattle: physiological and genetic aspects. Rev Bras Zootec. 2008;37:110-5. DOI: $10.1590 / \mathrm{S} 1516-35982008001300013$

Casati L, Celotti F, Negri-Cesi P, Sacchi MC, Castano P, Colciago A. Platelet derived growth factor (PDGF) contained in Platelet Rich Plasma (PRP) stimulates migration of osteoblasts by reorganizing actin cytoskeleton. Cell Adh Migr. 2014;8:595-602. PMID: 25482626 DOI: 10.4161/19336918.2014.972785

Chang Y, Li J, Chen Y, Wei L, Yang X, Shi Y, Liang X. Autologous platelet-rich plasma promotes endometrial growth and improves pregnancy outcome during in vitro fertilization. Int J Clin Exp Med. 2015;8:1286-90. PMID: 25785127

Coksuer $\mathrm{H}$, Akdemir $\mathrm{Y}$, Ulas Barut $\mathrm{M}$. Improved in vitro fertilization success and pregnancy outcome with autologous platelet-rich plasma treatment in unexplained infertility patients that had repeated implantation failure history. Gynecol Endocrinol. 2019;35:815-8. PMID: 30966843 DOI: $10.1080 / 09513590.2019 .1597344$
Colombo GVL, Fanton V, Sosa D, Criado Scholz E, Lotti J, Aragona SE, Lotti T. Use of platelet rich plasma in human infertility. J Biol Regul Homeost Agents. 2017;31:179-82. PMID: 28702979

Davis VL, Abukabda AB, Radio NM, Witt-Enderby PA, Clafshenkel WP, Cairone JV, Rutkowski JL. Platelet-rich preparations to improve healing. Part I: workable options for every size practice. J Oral Implantol. 2014;40:500-10. PMID: 25106016 DOI: 10.1563/AAID-JOI-D-12-00104

Dawood AS, Salem HA. Current clinical applications of platelet-rich plasma in various gynecological disorders: An appraisal of theory and practice. Clin Exp Reprod Med. 2018;45:67-74. PMID: 29984206 DOI: 10.5653/ cerm.2018.45.2.67

DeLong JM, Russell RP, Mazzocca AD. Platelet-rich plasma: the PAW classification system. Arthroscopy. 2012;28:998-1009. PMID: 22738751 DOI: 10.1016/j.arthro.2012.04.148

Deochand C, Tong M, Agarwal AR, Cadenas E, de la Monte SM. Tobacco Smoke Exposure Impairs Brain Insulin/IGF Signaling: Potential Co-Factor Role in Neurodegeneration. J Alzheimers Dis. 2016;50:373-86. PMID: 26682684 DOI: 10.3233/JAD-150664

Dhurat R, Sukesh M. Principles and Methods of Preparation of Platelet-Rich Plasma: A Review and Author's Perspective. J Cutan Aesthet Surg. 2014;7:189-97. PMID: 25722595 DOI: 10.4103/0974-2077.150734

Du L, Miao Y, Li X, Shi P, Hu Z. A Novel and Convenient Method for the Preparation and Activation of PRP without Any Additives: Temperature Controlled PRP. Biomed Res Int. 2018;2018:1761865. PMID: 29862255 DOI: $10.1155 / 2018 / 1761865$

Fabi S, Sundaram H. The potential of topical and injectable growth factors and cytokines for skin rejuvenation. Facial Plast Surg. 2014;30:157-71. PMID: 24810127 DOI: $10.1055 / \mathrm{s}-0034-1372423$

Facchin F, Somigliana E, Busnelli A, Catavorello A, Barbara $G$, Vercellini P. Infertility-related distress and female sexual function during assisted reproduction. Hum Reprod. 2019;34:1065-73. PMID: 31090897 DOI: 10.1093/humrep/dez046

Fang J, Wang $X$, Jiang $W$, Zhu $Y$, Hu $Y$, Zhao $Y$, Song $X$, Zhao J, Zhang W, Peng J, Wang Y. Platelet-Rich Plasma Therapy in the Treatment of Diseases Associated with Orthopedic Injuries. Tissue Eng Part B Rev. 2020;26:571-85. PMID: 32380937 DOI: $10.1089 /$ ten.teb.2019.0292

Farimani M, Bahmanzadeh M, Poorolajal J. A New Approach Using Autologous Platelet-Rich Plasma (PRP) to Treat Infertility and To Improve Population Replacement Rate. J Res Health Sci. 2016;16:172-3. PMID: 27840348

Farimani M, Heshmati S, Poorolajal J, Bahmanzadeh M. A report on three live births in women with poor ovarian response following intra-ovarian injection of platelet-rich plasma (PRP). Mol Biol Rep. 2019;46:1611-6. PMID: 30725347 DOI: 10.1007/s11033-019-04609-w 
Ferraretti AP, La Marca A, Fauser BC, Tarlatzis B, Nargund G, Gianaroli L; ESHRE working group on Poor Ovarian Response Definition. ESHRE consensus on the definition of 'poor response' to ovarian stimulation for in vitro fertilization: the Bologna criteria. Hum Reprod. 2011;26:1616-24. PMID: 21505041 DOI: 10.1093/humrep/der092

Gonçalves LF, Fernandes AP, Cosme-Silva L, Colombo FA, Martins NS, Oliveira TM, Araujo TH, Sakai VT. Effect of EDTA on TGF- $\beta 1$ released from the dentin matrix and its influence on dental pulp stem cell migration. Braz Oral Res. 2016;30:e131. PMID: 28001241 DOI: 10.1590/18073107bor-2016.vol30.0131

Grassi EA, Araujo MC. Antiplatelet: Growing knowledge. Disc Scientia. 2012;13:131-43.

Haahr T, Esteves SC, Humaidan P. Individualized controlled ovarian stimulation in expected poor-responders: an update. Reprod Biol Endocrinol. 2018;16:20. PMID: 29523204 DOI: 10.1186/s12958-018-0342-1

Jang HY, Myoung SM, Choe JM, Kim T, Cheon YP, Kim YM, Park H. Effects of Autologous Platelet-Rich Plasma on Regeneration of Damaged Endometrium in Female Rats. Yonsei Med J. 2017;58:1195-203. PMID: 29047244 DOI: 10.3349/ymj.2017.58.6.1195

Jo $\mathrm{CH}$, Roh YH, Kim JE, Shin S, Yoon KS. Optimizing platelet-rich plasma gel formation by varying time and gravitational forces during centrifugation. J Oral Implantol. 2013;39:525-32. PMID: 21480780 DOI: 10.1563/AAID-JOI-D-10-00155

Kahraman S, Cetinkaya CP, Cetinkaya M, Yelke H, Colakoglu YK, Aygun M, Montag M. The effect of follicle size and homogeneity of follicular development on the morphokinetics of human embryos. J Assist Reprod Genet. 2017;34:895903. PMID: 28470453 DOI: $10.1007 / s 10815-017-0935-1$

Kim H, Shin JE, Koo HS, Kwon H, Choi DH, Kim JH. Effect of Autologous Platelet-Rich Plasma Treatment on Refractory Thin Endometrium During the Frozen Embryo Transfer Cycle: A Pilot Study. Front Endocrinol (Lausanne). 2019;10:61. PMID: 30837945 DOI: 10.3389/fendo. 2019.00061

Lichtenfels M. Efeito do Plasma Rico em Plaquetas e de Plaquetas Rica em Fibrina na Regeneração de Lesões com Perda de Substância do Nervo Ciático em Ratos [Dissertation]. Porto Alegre: Pontifícia Universidade Católica do Rio Grande do Sul; 2012.

Malanga GA, Goldin M. PRP: review of the current evidence for musculoskeletal conditions. Curr Phys Med Rehabil Rep. 2014;2:1-5. DOI: $10.1007 /$ s40141-013-0039-5

Mazzucco L, Balbo V, Cattana E, Guaschino R, Borzini P. Not every PRP-gel is born equal. Evaluation of growth factor availability for tissues through four PRP-gel preparations: Fibrinet, RegenPRP-Kit, Plateltex and one manual procedure. Vox Sang. 2009;97:110-8. PMID: 19392780 DOI: 10.1111/j.1423-0410.2009.01188.x

Mishra A, Harmon K, Woodall J, Vieira A. Sports medicine applications of platelet rich plasma. Curr Pharm Biotechnol. 2012;13:1185-95. PMID: 21740373 DOI: $10.2174 / 138920112800624283$
Molina A, Sánchez J, Sánchez W, Vielma V. Platelet-rich plasma as an adjuvant in the endometrial preparation of patients with refractory endometrium. JBRA Assist Reprod. 2018;22:42-8. PMID: 29303234 DOI: 10.5935/15180557.20180009

Nayak S, Dinda A. Lower level laser therapy for pain management: an integrative review. Caribb J Sci Technol. 2015;3:744-51.

Noyes N, Liu HC, Sultan K, Schattman G, Rosenwaks Z. Endometrial thickness appears to be a significant factor in embryo implantation in in-vitro fertilization. Hum Reprod. 1995;10:919-22. PMID: 7650143 DOI: 10.1093/oxfordjournals.humrep.a136061

Pantos K, Simopoulou M, Pantou A, Rapani A, Tsioulou P, Nitsos N, Syrkos S, Pappas A, Koutsilieris M, Sfakianoudis K. A Case Series on Natural Conceptions Resulting in Ongoing Pregnancies in Menopausal and Prematurely Menopausal Women Following Platelet-Rich Plasma Treatment. Cell Transplant. 2019;28:1333-40. PMID: 31271054 DOI: $10.1177 / 0963689719859539$

Roh YH, Kim W, Park KU, Oh JH. Cytokine-release kinetics of platelet-rich plasma according to various activation protocols. Bone Joint Res. 2016;5:37-45. PMID: 26862077 DOI: $10.1302 / 2046-3758.52 .2000540$

Scherer SS, Tobalem M, Vigato E, Heit Y, Modarressi A, Hinz B, Pittet B, Pietramaggiori G. Nonactivated versus thrombin-activated platelets on wound healing and fibroblast-to-myofibroblast differentiation in vivo and in vitro. Plast Reconstr Surg. 2012;129:46e-54e. PMID: 22186584 DOI: $10.1097 /$ PRS.0b013e3182362010

Seyyed Anvari S, Dehgan GH, Razi M. Preliminary Findings of Platelet-Rich Plasma-Induced Ameliorative Effect on Polycystic Ovarian Syndrome. Cell J. 2019;21:243-52. PMID: 31210429 DOI: $10.22074 /$ cellj.2019.5952

Sfakianoudis K, Simopoulou M, Nitsos N, Rapani A, Pantou A, Vaxevanoglou T, Kokkali G, Koutsilieris M, Pantos K. A Case Series on Platelet-Rich Plasma Revolutionary Management of Poor Responder Patients. Gynecol Obstet Invest. 2019;84:99-106. PMID: 30134239 DOI: $10.1159 / 000491697$

Sills ES, Wood SH. Autologous activated platelet-rich plasma injection into adult human ovary tissue: molecular mechanism, analysis, and discussion of reproductive response. Biosci Rep. 2019;39:BSR20190805. PMID: 31092698 DOI: 10.1042/BSR20190805

Tarín JJ, García-Pérez MA, Hamatani T, Cano A. Infertility etiologies are genetically and clinically linked with other diseases in single meta-diseases. Reprod Biol Endocrinol. 2015;13:31. PMID: 25880215 DOI: 10.1186/s12958-015-0029-9

Zadehmodarres S, Salehpour S, Saharkhiz N, Nazari L. Treatment of thin endometrium with autologous platelet-rich plasma: a pilot study. JBRA Assist Reprod. 2017;21:54-6. PMID: 28333034 DOI: 10.5935/1518-0557.20170013

Zegers-Hochschild F, Schwarze JE, Crosby JA, Musri C, Urbina MT. Assisted reproductive techniques in Latin America: The Latin American registry, 2016. JBRA Assist Reprod. 2019;23:25567. PMID: 31364341 DOI: 10.5935/1518-0557.20190037 
Zhang X, Wang J, Ren M, Li L, Wang Q, Hou X. A novel collagen/platelet-rich plasma (COL/PRP) scaffold: preparation and growth factor release analysis. Cell Tissue Bank. 2016;17:327-34. PMID: 26951554 DOI: 10.1007/s10561016-9551-z
Zhou J, Peng X, Mei S. Autophagy in Ovarian Follicular Development and Atresia. Int J Biol Sci. 2019;15:726-37. PMID: 30906205 DOI: 10.7150/ijbs.30369 